\title{
Exploración del ethos del docente de español en Colombia ${ }^{1}$
}

\author{
Inquiry on the Ethos of Spanish Language Teachers in Colombia \\ Exploração do ethos do professor de espanhol na Colômbia \\ Giohanny Olave ${ }^{2}$ \\ Ilene Rojas García ${ }^{3}$ \\ Mireya Cisneros Estupiñán 4
}

\section{Resumen}

En este artículo se muestran los resultados parciales del análisis de un corpus de narrativas docentes. Los textos fueron escritos por profesores de español de nivel básico y medio en Colombia, y fueron recolectados a partir de una pregunta abierta sobre su experiencia docente. El objetivo de este análisis es explorar las imágenes que los docentes inscriben en sus discursos acerca de ellos mismos (ethos del docente). El trabajo muestra cómo se movilizan esas imágenes de sí mismos en los órdenes discursivos del contar y del comentar la experiencia en las aulas. Estas movilizaciones construyen tres imágenes subsidiarias del docente como sujeto experto: el ethos del profesional crítico, del intelectual innovador y del formador para la vida. El acercamiento realizado contribuye, por un lado, a plantear preguntas y posibles conexiones interdisciplinares con los estudios pedagógicos sobre las identidades docentes y, por otro lado, a la necesidad de escuchar las voces de los profesores en ejercicio al respecto de su ingreso y desempeño en el mundo laboral-escolar, después de haber sido preparados como profesionales de la educación, en general, y como didactas de la lingüística, en particular.

Palabras clave

ethos docente; educación lingüística; discurso profesoral; didáctica de la lengua materna

Abstract

This article presents the partial results of the analysis of a corpus of teaching narratives. The texts were written by elementarylevel and secondary-level Spanish language teachers in Colombia. The writing prompt was an open question about their teaching experience. The purpose of the analysis was to examine the teachers' self-image as shown in their discourses (their ethos). This is the standing point where postures about the social space of education in the country fall into. The paper shows how those selfimages move around the discourses of telling and commenting on classroom experiences. These movements prompt three subsidiary images of the teacher as an expert subject: the ethos of the critical professional, the innovative intellectual, and the educator for life. The approach carried out arises questions and suggests possible cross-curricular links with pedagogical studies on teaching identities. It also highlights the need to listen to teachers concerning their entrance and performance in the working-school world after being trained as education professionals, in general, and as linguistic teachers, specifically.

Keywords

teaching ethos; linguistic education; teaching discourse; didactics of mother tongue

\section{Resumo}

Neste artigo apresentam-se os resultados parciais da análise de um corpus de narrativas docentes. Os textos foram escritos por professores de espanhol de níveis básico e médio na Colômbia, e foram coletados a partir de uma questão aberta sobre sua experiência docente. 0 objetivo desta análise é explorar as imagens que os professores inscrevem em seus discursos sobre eles mesmos (ethos do professor). Estas construções são configuradas por meio da posta em cena das experiências do sujeito em seu rol professoral, lugar de enunciação desde o qual são inscritos posicionamentos no espaço social da educação no país. 0 trabalho evidencia como aquelas imagens de sim mesmos são mobilizadas nas ordens discursivas do contar e do comentar a experiência nas salas de aula. Essas mobilizações conformam três imagens subsidiárias do professor como sujeito experto: o ethos do profissional crítico, do intelectual inovador e do formador para a vida. A aproximação realizada contribui, por uma parte, para colocar questões e possíveis conexões interdisciplinares com os estudos pedagógicos sobre as identidades docentes e, por outra, para expor a necessidade de escutar as vozes dos professores acerca de seu ingresso e desempeno no mundo laboral-escolar, depois de se formar como profissionais da educação, em geral, e como didatas da linguística, em particular.

Palavras chave

ethos docente; educação linguística; discurso professoral; didática da língua materna

Artículo recibido el 15 de septiembre del 2016 y aprobado el 21 de diciembre del 2016

1 Artículo derivado de la investigación Enseñar a enseñar lingüística escolar: de la formación universitaria a la experiencia profesoral en didáctica de la lengua materna, adelantada en el grupo Estudios del Lenguaje y la Educación, durante el 2014 y el 2015, centrada en el diálogo disciplinar entre la lingüística aplicada y la didáctica de la lengua materna. Los resultados finales de la investigación mencionada se pueden leer en Cisneros, Rojas y Olave (2016a y 2016b).

2 Universidad de Buenos Aires, Buenos Aires, Argentina. Correo electrónico: olavearias@gmail.com

3 Universidad del Norte, Barranquilla, Colombia. Correo electrónico: dirojas@uninorte.edu.co

4 Universidad Tecnológica de Pereira, Pereira, Colombia. Correo electrónico: mireyace@utp.edu.co 


\section{Introducción}

En el marco de la investigación Enseñar a enseñar lingüística escolar: de la formación universitaria a la experiencia profesoral en didáctica de la lengua materna (Cisneros-Estupiñán, Rojas-García y OlaveArias, 2016a, 2016b), adelantada por nosotros como integrantes del grupo Estudios del Lenguaje y la Educación, adscrito a la Universidad Tecnológica de Pereira, Colombia, se muestran los resultados parciales del análisis de un corpus de escrituras docentes. Los textos pertenecen a profesores de español en escuela básica y media en Colombia y fueron recolectados a partir de una pregunta abierta sobre su experiencia profesional. El objetivo de este análisis inicial es explorar las imágenes que los docentes inscriben en sus discursos acerca de ellos mismos (ethos del docente). Estas construcciones se configuran por medio de la puesta en escena de las experiencias del sujeto en su rol profesoral, lugar de enunciación desde el cual se inscriben posicionamientos en el espacio social de la educación en el país.

Nuestra investigación se ubica en el campo de la lingüística escolar, entendida como el conjunto de saberes sobre la lengua materna que son conducidos, transformados y producidos a través de diversos dispositivos escolares, entre ellos, la clase misma. Nos interesa el docente de lenguaje y su relación con los procesos de formación -institucionales, pero también empíricos- como profesional de la enseñanza. Seguimos con esto un sinnúmero de investigaciones pedagógicas que han revalorado la voz del docente como objeto de estudio, en general (Hargreaves, 1996), y las narrativas sobre sus historias de vida profesional, en particular (Bolívar, 2014; Bolívar y Domingo, 2006; Goodson, 2003, 2012; Jackson, 1996; McEwan y Egan, 1998; Clementino de Souza, Serrano y Ramos, 2014). Sin embargo, no asumimos una perspectiva de investigación pedagógica, sino que nos ubicamos en un punto de cruce de la didáctica con la retórica y sus herramientas analíticas. En particular, nos interesa la noción de ethos discursivo como categoría conceptual que nos sirva para escuchar las voces de los docentes.

Por esto, el presente trabajo muestra cómo se movilizan esas imágenes de sí mismos, en los órdenes discursivos del contar y del comentar la experiencia en las aulas. Estas movilizaciones construyen tres imágenes subsidiarias del docente como sujeto experto: el ethos del profesional crítico, del intelectual innovador y del formador para la vida.

El acercamiento realizado contribuye, por un lado, a plantear preguntas y posibles conexiones interdisciplinares con los estudios pedagógicos sobre las identidades profesionales docentes; $y$, por otro lado, a la necesidad de escuchar las voces de los profesores en ejercicio, al respecto de su ingreso y desempeño en el mundo laboral-escolar, después de haber sido preparados como profesionales de la educación, en general, y como didactas de la lingüística, en particular. A manera de conclusión, presentamos una síntesis del artículo, sus aportes en relación con el proyecto de investigación del cual se deriva y una proyección del trabajo, para la continuidad de las indagaciones en los intereses del grupo Estudios del Lenguaje y la Educación.

\section{Fundamentación teórica}

El punto de vista discursivo de la comunicación ha recuperado la categoría de ethos de la retórica clásica, en la que se le refería como un medio de persuasión a través del cual el orador ganaba la confianza de su auditorio poniéndose él mismo como garante de su palabra (Aristóteles, 2010). Desde la perspectiva de Amossy (2010, p. 15), no se trata solamente de una necesidad de probar y persuadir, sino que la construcción de la imagen de sí mismo a través de la propia palabra es inherente a la comunicación humana; está en el centro de todos los discursos que circulan en el espacio social, toda vez que decir es revelarse a sí mismo:

diciendo "yo", el locutor construye en su enunciación una imagen de sí al mismo tiempo que se constituye en sujeto. Es a través de esta imagen que él se identifica - que él se da a ver- de una forma que permite situarlo socialmente y distinguirlo individualmente por unos rasgos particulares. Cualesquiera que sean los datos preexistentes que posee el interlocutor sobre el sujeto hablante, el uso de la lengua los retoma y recrea. Esto entraña una dinámica intersubjetiva donde son renegociados 
el "quién soy yo para mí", "quién soy yo para ti" y, sobre todo, "quién quiero ser para ti". (Amossy, 2010, p. 105, traducción propia).

Ahora bien, la noción de ethos desde el análisis del discurso no se limita a la descripción de unos rasgos personales que el locutor se autoatribuye en función de alcanzar un propósito. En vez de esa visión instrumentalista del lenguaje, a partir de los aportes de las perspectivas sociológicas sobre la noción de ethos (Montero, 2012), se entiende que los sujetos hablantes están influidos permanentemente por las instituciones sociales dentro de las cuales viven y por elementos estructurantes de la historia y de su lugar en el mundo. El ethos construido ancla, entonces, en un conjunto amplio de creencias, valores, estereotipos e imaginarios compartidos; en fin, de representaciones culturales e ideológicas que, al mismo tiempo, dejan su huella en los recursos y procedimientos retóricos a través de los cuales los sujetos se presentan a sí mismos.

Mainguenau (2009, p. 209) resume esta visión discursiva del ethos en tres características definitorias: (1) es una noción discursiva, no una construcción exterior a la palabra, pero no es exclusiva de la oralidad ni de la interacción cara a cara; (2) está vinculado a un proceso interactivo de influencia del otro u otros (personales, institucionales, culturales, históricos, etc.); y (3) es una noción comunicativamente situada, que debe examinarse en la situación específica en que se produce y en su coyuntura sociohistórica. El mismo autor distingue, además, desde el punto de vista del productor, entre un ethos dicho (cuando el enunciador habla sobre sí mismo) y un ethos mostrado (los aspectos inscritos en el texto que quedan como huellas de la autoconcepción que vehicula una imagen a construir: estilo, tono, procedimientos, relaciones, etc.); desde el punto de vista de la recepción, se habla también de un ethos previo (representaciones de la imagen del locutor: su prestigio o fama) y un ethos efectivo (la imagen del locutor que construye el destinatario) (Maigueneau, 2009, 2014). Estas instancias discursivas aparecen imbricadas en la enunciación y su delineamiento e interpretación constituyen un eje analítico para explorar el decir de los sujetos sociales.
Con el eje del ethos discursivo, en la actualidad no existe exploración visible sobre las voces docentes. No obstante, una preocupación ligada a esta problemática es, sin duda, la pregunta por la identidad profesional docente, campo en el que sí se ha desarrollado una nutrida reflexión. Esos estudios atienden, en general, a lo que Arostegui (2004, p. 360) identifica como la pregunta por la acción transformadora en las sociedades actuales, desde el reclamo de identidades diferenciadas, esto es, la búsqueda del reconocimiento de las singularidades étnicas, regionales, lingüísticas, religiosas, profesionales, etc., como agencias críticas contra la homogenización de las subjetividades.

En ese marco, la definición de identidad profesional docente ha sido inestable y compleja. La búsqueda elaborada por Tezanos (2012, p. 13) a este respecto concluye que no existe una definición compartida por los investigadores, si bien es en la exploración en torno a "las narrativas de los profesores donde surge el acuerdo que relaciona el significado de la identidad profesional con el conocimiento práctico personal de cada entrevistado y vinculado a la noción de historias vividas por". Desde esa perspectiva de la narración docente, Bolívar y Domingo (2006) han definido la identidad profesional como un producto de la interacción entre experiencias profesionales (trayectorias biográficas) y el entorno de los sujetos (sociedad, cultura e instituciones donde se encuentran insertos). Hay que resaltar que los estudios sobre identidad docente usualmente la refieren en términos de formas de ser y actuar, esto es, como roles sociales que se configuran a lo largo de la vida profesional y que van construyendo autoconcepciones o autoimágenes en los profesores.

$\mathrm{Al}$ respecto de esas imágenes, Tedesco y Tenti (2006, p. 62) reconocen, desde una mirada histórica, tres tipos de maestros: el maestro sacerdote-apóstol, el trabajador-militante y el maestro técnico-profesional. Estos modos del ser docente dan cuenta de unos estereotipos sociales o de figuras idealizadas en las diferentes coyunturas históricas, pero que coexisten en tiempos, lugares e instituciones.

Por su parte, en estudios empíricos, como el de Rivas, Sepúlveda y Rodrigo (2005), se comprueba 
que los docentes suelen idealizar su rol social y sus propias prácticas cuando hablan acerca de su trabajo, posición "desde la que pretenden darse explicaciones y justificaciones sobre sí mismos, así como sobre la imagen que proyectan de cómo es su práctica profesional" (Rivas, Sepúlveda y Muñoz, 2005, p. 3). En este sentido, la búsqueda de la voz de los docentes no es funcional a la investigación que pretenda evaluar lo que hacen ellos en las aulas, la calidad de la enseñanza, el impacto en el aprendizaje, etc. Es claro que la pregunta por la identidad profesional docente, en la reflexión pedagógica, no tiene que ver con esos intereses evaluativos.

En general, los estudios sobre identidades docentes parecen articulables con la pregunta por el ethos discursivo de los profesores. Esas formas de articulación plantean desafíos que desbordan este artículo, pero se trata de una vía de análisis que pretendemos poner sobre la mesa para su discusión. Compartimos, con Vaillant (2007, p. 4), que la identidad del docente puede concebirse "como la definición de sí mismo que hace el docente"; aunque no se agota en esa dimensión, sí le es constitutiva.

\section{Metodología}

Conformamos una muestra aleatoria de 17 escrituras producidas por docentes de español como lengua materna en instituciones colombianas de educación básica y secundaria, privadas y públicas. Las escrituras se recolectaron como parte del diseño metodológico de la investigación referida antes (Cisneros, Rojas y Olave, 2016a, 2016b) y pertenecen a su base de datos. Formulamos una consigna abierta que invitaba a los docentes a relatar una experiencia vivida durante su ejercicio profesional:

A partir de su trabajo como docente de Español, relate una experiencia vivida de la cual haya aprendido algo valioso para la enseñanza de la lengua, y cómo obtuvo ese aprendizaje. Procure que en su relato aparezcan las siguientes palabras, en cualquier orden: gramática, lenguaje, lingüística, texto, discurso, universidad. Finalmente, titule su narración. No importa la extensión del relato.
En este artículo, utilizamos la categoría teórica de ethos como principal herramienta analítica para el corpus, desde la perspectiva francesa del análisis del discurso y particularmente desde los trabajos de Mainguenau (2009, 2014) y Amossy (2010). Con esta categoría analizamos los discursos docentes de manera exploratoria, con lo cual buscamos definir las imágenes de sí mismos que ellos construyeron y pusieron en la escena de sus escrituras. El procedimiento se ajustó a mecanismos de análisis inferencial inductivo-deductivo, según los tipos de codificación que propone la teoría fundamentada (Strauss y Corbin, 2002): codificación abierta y axial y selectiva.

A través de la primera, abierta, se leyeron los discursos de los docentes buscando anclajes textuales o huellas de las imágenes de sí en el discurso. El paso hacia la codificación axial se dio a través de la precategoría analítica ethos, para delinerar tres categorías emergentes, según las regularidades que fue arrojando el corpus. Esas categorías fueron nombradas como "profesional crítico", "intelectual innovador" y "formador para la vida". Así esbozadas, se procedió a recodificar selectivamente las categorías emergentes, con lo cual se buscó describirlas, ejemplificarlas con citas del corpus y relacionarlas interpretativamente con lo que llamamos "ethos de la experiencia" como ethos dominante, resultado del análisis categorial que nos permitió relacionar entre sí las descripciones alcanzadas y que presentamos en la siguiente sección.

\section{Resultados}

\section{El docente como sujeto de la experiencia: un ethos dominante}

Las diferentes huellas del ethos en la escritura de los docentes transparentan una fuerte estimación positiva de la experiencia en el aula como la verdadera formadora del profesional de la enseñanza. Los profesores hacen ver que es su vivencia en las aulas reales la que los hace conscientes del hiato entre la formación docente y la práctica laboral; al hacerlo, se posicionan como sujetos que van 
aprendiendo y se van haciendo profesores a través de la experiencia, en un proceso que presentan como esencialmente continuo:

El conocimiento se adquiere en el día a día del aula; solo hasta que se ingresa a ella [...] se inicia la adquisición de los pasos para aprender las estrategias con las que se va asimilando la forma como el estudiante puede aprender. (E-12) .

Mi experiencia y aprendizaje como docente es continua y nunca terminará; considero que cada encuentro con el estudiante es una nueva experiencia y un nuevo aprendizaje. (E-10).

Como se destaca en las cursivas de las citas, el profesor se presenta a sí mismo como un profesional que, forjado por la experiencia en el día a día del aula, está autorizado para señalar el requisito o condición principal del conocimiento didáctico: las estrategias para la enseñanza se adquieren paso a paso, se van asimilando, es decir, no se cuenta con ellas sino hasta que la experiencia las va proporcionando en el quehacer docente. Solo el profesor experimentado, como se muestra a sí mismo, reconoce que su profesión consiste en ese aprendizaje, continuo y empírico, de la enseñanza, que además nunca terminará. Es interesante señalar, además, la representación del aula como el espacio-fuente donde se adquiere el conocimiento didáctico y, por tanto, donde ese sujeto de la experiencia lo puede encontrar, no como saber estático, sino como dinámica que emerge de la contingencia en el día a día.

Esa valoración positiva de la experiencia hace que en los textos se insista en remarcar los años de labores desarrolladas en la profesión docente,

5 Los textos producidos por los docentes han sido, en ocasiones, adecuados ortográfica y gramaticalmente para garantizar su legibilidad. Nos permitimos esas intervenciones formales, dado que el objetivo de este análisis no es la revisión del desempeño lingüístico-textual en la escritura de los docentes; por supuesto, hemos cuidado la fidelidad al sentido de sus comunicaciones. Todas las cursivas han sido añadidas para anclar en ellas las diversas aproximaciones interpretativas. El código que aparece entre paréntesis, al final de cada cita, es un número de identificación del texto en la base de datos de la investigación. Por razones de protec ción a la privacidad de los colaboradores, no se indican los nombres específicos de los profesores-autores. regularmente al hacer foco temático ${ }^{6}$ en ellos antes de presentar los aprendizajes adquiridos empíricamente:

En mis años de docencia (22) de profesor de Español o Lengua Castellana en el bachillerato y ahora en la universidad, he evidenciado grandes desarrollos de mis estudiantes alrededor de la siguiente práctica [...]. (E-10).

En el transcurso de los tres últimos años [...], descubrí, viviendo y sintiendo la experiencia, cómo el teatro aportaba en el aprendizaje de la lengua de una forma lúdica, creativa y motivadora para los estudiantes. (E-1).

Después de ocho años [...], puedo decir con certeza que la enseñanza de la lengua es la base principal para la aplicación pertinente de las estrategias que le permiten al estudiante, cualquiera que sea su edad, apropiarse de los modos de aprender las diferentes ciencias. (E-12).

Experiencias de este tipo son las que pude desarrollar durante ocho años en el colegio [...], base y riqueza práctica que me permitirán otras exploraciones didácticas en el aula. (E-17).

La autoridad que esos años de labores le darían al docente le permiten, al mismo tiempo, autorizarse a sí mismos para posicionar una visión particular sobre la didáctica de la lengua materna. En el caso del testimonio de E-10, resaltar las dos décadas en el ejercicio docente construye un ethos del profesional experto, movilizado tanto en el bachillerato como en la universidad, experticia que es mostrada como causa de los grandes desarrollos alcanzados a través de prácticas didácticas particulares. Ese mismo efecto de destreza, propio del experto, aparece en la construcción retórica asertiva de E-12, a través de la cual la certeza sobre la función cognoscitiva de la lengua es un producto de la observación realizada durante los años profesionales, es decir, se trata de un

6 Desde la perspectiva de la lingüística sistémico-funcional, una de las funciones de las construcciones textuales con tema marcado (en las cuales el punto de partida es un dato circunstancial, no el agente de la acción o del proceso) es remarcar, como organizador del sentido el contenido de la circunstancia que se ubica al inicio de la cláusula (Montemayor-Borsinger, 2004). 
saber teórico que solo se consolida como cierto $-\mathrm{y}$ adquiere estatuto de conocimiento veraz- a través de su emergencia en las prácticas.

Ese es el sentido de lo que es denominado como riqueza práctica en la escritura de E-17, para quien el ethos construido por el docente añade a la experticia la inquietud o curiosidad del explorador. En esta medida, el texto presenta la didáctica de la lengua materna como una exploración constante en el aula a través de experiencias de trabajo como la que relata y comenta en su testimonio. E-1, por su parte, moviliza junto al ethos experto la importancia de las emociones en el aprendizaje de la lengua, de lo cual el docente mismo es partícipe al mostrarse como el sujeto que se involucra y compromete directamente con la experiencia de trabajo (descubrí, viviendo y sintiendo la experiencia). En este caso, la didáctica de la lengua se liga con el desarrollo de formas artísticas, como el teatro, para remarcar la función poiética y social de la lengua en el proceso de enseñanza y aprendizaje escolar. En esta escritura se ejemplifica, además, cómo la experiencia es condición del descubrimiento de saberes (de ahí que la construcción en gerundio constituya el inciso explicativo del relato sobre esa acción del descubrir). En otras palabras, se trata de un ethos docente experto, en tanto que experimentado, vivido y sentido durante años de labor en las aulas. La escritura de E-9 muestra, desde otro modo de inscripción de la relación experiencia-experticia, una valoración fuerte de la experiencia de los otros:

Como podrá aproximarlo cualquier docente experimentado en este nivel educativo, aquellos apuntes no sintetizaban las proposiciones fundamentales de la lección, es decir, mis estudiantes no estaban reconstruyendo adecuadamente la estructura semántica de lo que planteaba. (E-9).

El comentario con el que inicia la cita a propósito de la anécdota agrupa valorativamente a los profesores según sean experimentados o no experimentados. Solo los primeros pueden prever lo que el docente cuenta que descubrió después de haberse equivocado. El autor se presenta a sí mismo como un sujeto que ha adquirido un saber que su grupo de identificación comparte. Ese grupo es el de los docentes experimentados, que han aprendido ciertas claves didácticas en el terreno, por ejemplo, que los estudiantes tienen dificultades para que su toma de apuntes reconstruya la lección magistral. En el mismo testimonio, más adelante se refuerza esta idea del saber experiencial que conforma un ethos colectivo de identificación con los pares:

De allí aprendí una valiosa lección que, no obstante, me tomó tiempo incorporar a la rutina: es importante señalar en el tablero y en el inicio de la explicación el título preciso de la temática. Así que el primer fallo de síntesis semántica fue mío, al no aclarar el índice textual que sería eje del discurso. (E-9).

Las lecciones son valiosas precisamente porque hay un proceso extendido para su incorporación a lo que E-9 denomina la rutina, esto es, a las prácticas habituales de los docentes experimentados. El resaltado en la cita enfatiza la dimensión cognoscitiva atribuida a las vivencias relatadas, que tiene su impacto en las prácticas didácticas del quehacer diario.

Uno de los puntos más importantes que como docente de la asignatura de Español se puede aprender en el aula es que el entorno es muy influyente y los estudiantes imitan lo que ven en él, no solo porque los chicos a esta edad no quieren quedarse rezagados [...], sino porque, de tanto repetirse una palabra entre ellos, o un hábito, se considera una rutina normal; por ejemplo, las palabras soeces en el trato diario. (E-12).

luego de escuchar a sus compañeros, el estudiante me dijo: "profe, ya entendí qué son los adjetivos: son las cualidades y defectos únicos que me diferencian de mis compañeros y de cualquier otra cosa". Con ese pequeño ejercicio confirmé que la mejor forma de aprender es con la ejemplificación. (E-5).

Los aprendizajes que reportan los docentes, como vemos en los ejemplos, tienden un puente entre la didáctica específica de la lengua materna y la didáctica general. Desde su mirada, lo que el profesor aprende en el aula desborda la disciplina concreta y se intersecta con las formas de vida de los 
estudiantes, sus modos de relacionarse y de adquirir saberes. El docente no privilegia la presentación de la imagen de "el que enseña", sino del sujeto que aprende. Ese ethos del aprendizaje parece tomar distancia de los denominados "saberes sabios" (Chevallard, 1991) y pone en primer plano los saberes de la experiencia: el futuro educador, al momento de desempeñar su labor, se ve sin las herramientas más básicas, necesarias para enseñar, posteriormente, otros asuntos más "intelectuales" (E-9).

A partir de ese posicionamiento, el docente generaliza su propia experiencia de formación y de ingreso al ámbito laboral, al hablar de el futuro educador como aquel que no alcanza a dimensionar la diferencia entre la realidad del aula y la preparación que recibió para enfrentarla. Lo que presenta como las herramientas más básicas, en contraposición a los asuntos más "intelectuales", se refiere a esos saberes de oficio (Alliaud, 1998) que valora positivamente tanto en el presente de su labor como en la retrospectiva de su formación universitaria. En ese posicionamiento ejemplificado en E-9, se imbrica el ethos de la experiencia con otro que le es subsidiario: el ethos del profesional crítico.

\section{El ethos del profesional crítico}

En este apartado ejemplificaremos las huellas de la imagen del docente como profesional que se autoriza a sí mismo para criticar diversos aspectos de las dinámicas escolares. Este ethos se desprende, insistimos, de la imagen del sujeto de la experiencia que funciona como marco o como ethos dominante. Con el sintagma profesional crítico aludimos a la inscripción de juicios de valor, sin calibrar sus grados de elaboración, complejidad ni argumentación, y ligamos esos juicios, tanto dichos como mostrados, con la autoimagen del profesional de la enseñanza que construyen los docentes, esto es, con su rol constituyente en la idea que se forman de sí mismos como profesores.

Un aspecto común en los testimonios es la referencia crítica a su propia formación universitaria, a partir de la cual tensionan el buen recuerdo de sus años como estudiantes con el contraste de la realidad de las aulas, cuando ya se han insertado en el mundo laboral:

Considero valiosa la educación que recibí en mi pregrado, pero también me reservo, como es natural, algunas posiciones críticas. Una de ellas es que la academia, o por lo menos la parte de ella donde me eduqué, en general parecía centrada más en formar lingüistas y literatos que en formar licenciados [...]. Es un gran error el confiar en que un maestro pueda ir a "sentarse en la palabra" en la secundaria, como lo creía uno de mis compañeros de clase que se autodenominaba "progresista". (E-9).

En la dicotomía entre la disciplina del lenguaje y la formación docente se encuentra el núcleo de la valoración negativa que hace el docente. Frente a esta dicotomía, establecida desde la mirada a posteriori del profesor, es claro que el reclamo se decanta por la formación de docentes, más que de científicos e, inclusive, de académicos, como queda en evidencia en la segunda parte de la cita. No es este el lugar para discutir el problema de esa dicotomía y de su imaginario, sino que nos interesa resaltar que, en la construcción del ethos del docente, aparece funcionando como el establecimiento de una posición crítica frente a la preparación universitaria para la vida del trabajo. En la cita, no es menor la función de la ironía para mostrarse como el profesional crítico, en contraposición con los "progresistas", quienes, al pretender que la enseñanza consiste en "sentarse en la palabra", ignorarían la mayor importancia del saber-enseñar, más que del saber-saber. En otras palabras, el ethos del profesional crítico asume la defensa del saber didáctico situado y relativiza la centralidad universitaria del saber científico descontextualizado. A través de ese mismo ethos, los docentes diagnostican la realidad de la educación, usualmente de manera negativa:

Es común que, en nuestras escuelas, la situación de la enseñanza del lenguaje presente dificultades diversas; es evidente que las estrategias implementadas para el desarrollo de los procesos de pensamiento no han producido los resultados esperados. (E-14). 
En la práctica de esta estrategia, pude reflexionar acerca de las prácticas pedagógicas que se han mantenido a lo largo de la formación del lenguaje en las escuelas y colegios, centradas en la transmisión de conocimientos de lingüística y gramática, en donde muchas veces el estudiante es un mero receptor de información y no el principal actor de su aprendizaje. (E-1).

En E-14, el marcador discursivo resaltado modaliza la crítica a la enseñanza usual al presentar su visión negativa como compartida desde la evidencia. Esta inscripción de juicios de valor antecede, en los testimonios, a la descripción de experiencias de aula propias que reaccionan contra ese diagnóstico en crisis de la educación lingüística. Esto significa que los segmentos de la crítica sirven para amplificar positivamente las experiencias relatadas y comentadas por los docentes. Como se resalta en E-1, esas prácticas llevan a la reflexión sobre la inconveniencia de la enseñanza usual, de manera que se valoran también en el sentido de la transformación que operan a nivel del docente como profesional reflexivo. Es en ese mismo sentido que en E-11 el relato de una experiencia didáctica alrededor de la disposición de la clase y del aula de español como cafés literarios introduce una crítica a la estructura escolar, mitigada bajo la metáfora del regimiento militar:

del salón de clase se trasformó y un halo de aromas deliciosos embriagó el espacio cotidiano [...]. Ahora las palabras eran más que simples elementos de una oración; los estudiantes habían logrado sumergirse en el océano de los símbolos y desentrañar los significados de lo visual. El café se hizo galería y taller. 12:00 del día: el timbre sonó anunciando el cierre del establecimiento; las mesas fueron nuevamente pupitres de colegio y el aula recibió con su alineación perfecta y milimétrica marcial al siguiente profesor [...]. (E-11).

El juego metafórico en E-11 contrasta dos visiones de la didáctica de la lengua materna a través de la contraposición cuartel militar/café literario. Ese juego le permite al docente mostrar su inconformidad con la primera visión y presentar la segunda, la suya, como el espacio valioso y significativo para el aprendizaje de los estudiantes, aunque temporal y limitado por una estructura escolar rígida y una perspectiva simplificante de la lengua como estructura verbal y formal. El docente se afilia a la metáfora del café literario de su relato y con ello se diferencia de los otros profesores, a quienes asocia con la metáfora del cuartel militar. En este movimiento retórico, la imagen construida es la del profesional que critica unos ciertos modos de hacer y de pensar la educación lingüística y la escuela misma. Si bien, en E-11, ese posicionamiento está mitigado por el juego metafórico, en otras escrituras se muestra de manera más directa la crítica a aspectos de la estructura escolar, entre ellos, la posición frente al desempeño de los colegas:

Para nosotros es complicado hacer el trabajo que muchos de los profesores omitieron durante años en educación básica, secundaria y media secundaria; suplir ese ciclo formativo es mucho más difícil en el área de lenguaje. (E-3).

Urge que se enseñe a escribir, que se enseñe a leer y se retome, si es necesario, desde la construcción básica. Ahora bien, no puede el docente dar de lo que no tiene; si él mismo apenas está aprendiendo a escribir, ¿cómo va a enseñarlo? (E-12).

En clave procesual de los aprendizajes, es usual que los docentes critiquen los vacíos formativos que presentan sus estudiantes como parte de la escolarización en estadios anteriores. La debilidad de esos ciclos de aprendizaje, según su visión, es muy grave en el campo de la educación lingüística, dadas las transformaciones y la especialización de las demandas de la lectura y la escritura a medida que los alumnos avanzan en su trayectoria escolar y se enfrentan a nuevos contextos comunicativos, como el ciclo medio, el universitario y el profesional. En todos esos niveles, la comprensión y producción textual es parte fundamental de la formación en las diversas disciplinas y en la metadisciplina misma; por esta razón, la suplencia de los vacíos formativos es presentada como un desafío, complicado y difícil, en E-3, pero necesario. En este sentido, la preparación de los docentes deviene en urgencia, como se plantea en E-12. La crítica, en este caso, se dirige a las competencias lectoras y escritoras de los propios docentes, quienes no pueden enseñarlas si 
no demuestran que las han desarrollado en su propio desempeño cualificado. El docente, en suma, debe experimentar en carne propia y dar ejemplo con sus competencias comunicativas. Algunos testimonios avanzan, a partir de esta visión, hacia la imagen del docente como un intelectual innovador.

\section{El ethos del intelectual innovador}

En esta imagen de sí mismos, los docentes orientan sus escrituras hacia la elaboración de un registro con rasgos genéricos propios del discurso académico (Castelló, 2007). Esa imagen construida se deja ver en la inclusión de citas, directas e indirectas, y la puesta en escena de referentes teóricos y conceptuales a propósito de la educación lingüística. Los relatos, por momentos, asumen la forma expositiva propia del reporte de investigación e introducen en el registro del discurso teórico sus aportes en forma de experiencias llevadas a cabo en las aulas:

Isabel Solé dice que "el lector debe darle sentido propio al texto para poder comprenderlo", y eso fue lo que noté en mis alumnos: la falta de sentido. (E-2).

En su teorización y práctica en el aula, las distintas reformas educativas tienden al desarrollo intelectual del niño. En el caso de lenguaje, los lineamientos curriculares, los estándares y las competencias fundamentan el planeamiento de actividades que coadyuvan al fortalecimiento de la capacidad comunicativa [...]. En tal sentido, se puede aplicar un análisis textual en el que se evalúen aspectos semánticos, sintácticos, pragmáticos y estéticos. La textolingüística, para enfocar su estudio, afirma que tanto una palabra, una oración, así como una novela, en su extensión, son textos susceptibles de ser analizados en cuanto a su cohesión, coherencia y funcionalidad. (E-15).

La preocupación por mostrar que se domina, con cierta rigurosidad teórica, el campo del saber lingüístico forma parte de la construcción de una imagen del docente como intelectual. En los textos citados, los referentes teóricos autorizan las observaciones del profesor en sus contextos de acción: la lectura de la realidad es relacionada con los saberes expertos y el intento de desplegar estos últimos en la escritura contribuye a que el docente dialogue con esos saberes a partir de su propia experiencia.

No obstante, en otros relatos, el ethos del intelectual innovador se resuelve menos en los referentes ajenos y más en el énfasis en las propuestas de trabajo propias. Esas innovaciones suelen estar ligadas a los posicionamientos críticos mostrados; por ejemplo, a partir de una valoración negativa de los libros de texto para la enseñanza de la lengua, el docente propone que

para mejorar los materiales de trabajo en el aula, el docente podría contar con una serie de cartillas (guías de aprendizaje) diseñadas por él para orientar sus clases y que los estudiantes fotocopiaran para cada periodo escolar [...]. Esto sería más factible si el pregrado de licenciatura propiciara espacios para que los futuros docentes diseñaran, por lo menos, el juego básico de sus futuras herramientas. (E-9).

La iniciativa de la elaboración propia de guías de trabajo apunta a resolver la problemática que el mismo docente plantea, en torno a la inconveniencia de los materiales editoriales. Además, en el texto se avanza hacia la preocupación por la factibilidad de esa propuesta y se introduce, en clave condicional, una opción para el espacio de la formación docente universitaria. El docente, entonces, problematiza y orienta una resolución general para la profesionalización desde su posición de profesor innovador en las aulas. El énfasis estriba aquí en mostrarse como el agente reflexivo y performativo de los problemas que él mismo plantea en torno a la educación lingüística. En E-11 aparece también esa imagen orientada, a propósito de una experiencia didáctica en cuya narración se hace hincapié en las transformaciones positivas alcanzadas por el docente:

Esta vez la gramática del lenguaje no las atormentaba. Casi podría decirse que habían logrado encontrar una fisura misteriosa en los renglones de sus textos favoritos, en el cual justificar el orden de los sustantivos, verbos y adjetivos. Por fin, toda esa maraña gramatical se había trasformado en un placer misterioso, que las atrapaba y al que deseaban encarnar. (E-11). 
El trabajo didáctico desarrollado transforma la visión negativa de la gramática y la conecta directamente con formas subjetivas del placer intelectual. La reiteración del descubrimiento de lo misterioso recaba sobre la idea de unos saberes lingüísticos que, a partir de didácticas innovadoras, reconvierte el aprendizaje en algo más cercano al placer que al deber escolar. Lo mostrado aquí es el docente mismo en su posición de guía hacia la satisfacción producida por la labor intelectual del que descubre y aprende.

Finalmente, el mismo ethos también se construye desde la conexión de las experiencias docentes con sus trabajos de investigación académica. Los relatos no solo integran esos procesos de formación profesional, sino que además los remarcan positivamente como fuentes que abren las posibilidades de innovación y, al mismo tiempo, las sustentan y justifican:

Sin duda, una experiencia fascinante fue mi trabajo de investigación en topoanálisis realizado para optar al título de Especialista en Docencia del Español y la Literaura [...]. Fue un aprendizaje valioso puesto que a partir de la poetización del espacio, se nos permite vivir la imagen como elemento fundamental en la poesía y de renovación espiritual del hombre, del conocimiento y de apertura hacia el razonar. (E-13).

Los trabajos de investigación desarrollados en el marco de posgrados en pedagogía permiten la introducción de innovaciones en el aula, a partir del enriquecimiento conceptual que el docente reporta. El ethos del intelectual innovador imbrica, entonces, la adquisición y dominio de esos saberes especializados con su puesta en práctica en propuestas de trabajo que renueven la enseñanza y aprendizaje de la lengua materna. Las innovaciones intelectuales aparecen en las escrituras docentes como modos de legitimar su oficio y dignificar la profesión, por lo cual no solo refieren experiencias de trabajo, sino también autopresentaciones positivas de sí mismos, en la búsqueda del reconocimiento en los ámbitos social y cultural:

Mi quehacer docente involucra lo pedagógico, lo didáctico y lo investigativo, por lo que incluyo modelos, enfoques y tendencias de enseñanza de las lenguas y recreo elementos innovadores para el aprendizaje del discente [...]. Esta ha sido una de las mejores experiencias, a partir de la cual publiqué un libro con textos inéditos [...]. Mi metodología propone una manera de argumentar y sustentar desde una nueva perspectiva motivacional y educativa, que busca integrar saberes e impactar positivamente en el porvenir tanto del estudiante como del docente. (E-16).

En el resaltado, indicamos cómo la cuestión del impacto social justifica la búsqueda intelectual de innovaciones para la enseñanza de la lengua. Desde la perspectiva de los docentes, ese impacto da cuenta de una cierta labor misional, en la cual se imbrica otro aspecto del ethos de la experiencia: el ethos del formador para la vida.

\section{El ethos del formador para la vida}

La autoimagen del educador como un formador para la vida personal y social de sus estudiantes ancla en un imaginario compartido sobre la labor docente como vocación y, en cierta medida, como sacrificio. Esta orientación de la representación social del profesor se relaciona con el declive del prestigio social de su profesión y el impacto de ese declive en la identidad profesional, sobre lo cual la bibliografía pedagógica ha reflexionado ampliamente (por ejemplo, Esteve, 1987, y más recientemente, Cuenca, 2015). En ese sentirse minusvalorado socialmente, la recuperación del reconocimiento se resuelve en el remarque de la profunda vocación requerida para ser docente, así como en el énfasis en las dificultades implicadas en su labor:

Primero hay que aclarar que la institución donde laboro tiene un horario académico bastante riguroso, ya que la entrada es a las 7:00 am y la salida es a las 5:00 pm, de lunes a viernes [...]. Realmente ha sido un trabajo duro sobre todo porque los jóvenes tienen una apatía tenaz frente a los libros y la lectura. (E-6).

Hubo situaciones en las que se invirtieron cuatro días preparando una clase de cuarenta minutos: cartelera, material para entregar con las preguntas del cuestionario, construir las preguntas, escoger el tema, analizar la lista de estudiantes 
para concretar el tema que fuera pertinente para ellos, buscar y recortar los materiales, elaborar la planilla de planeación de clase, simular la clase y medir el tiempo. (E-12).

Los docentes expresan esas dificultades (institucionales, laborales, procedimentales, etc.) para demostrarle a la sociedad el valor de su trabajo. Se trata de un esfuerzo anidado en una contradicción política: existe consenso en la función social de la educación y se le valora públicamente como una prioridad en el desarrollo de los países; pero, al mismo tiempo, la profesión docente es cada vez menos valorada culturalmente y no constituye una opción de primer orden en los proyectos profesionales demandados desde la escuela media. En esta medida, el docente autovalora su profesión desde el punto de vista de la vocación como apasionamiento:

Respecto a nuestra profesión, está en nosotros reflexionar constantemente sobre nuestra vocación, sobre aquello que hacemos en las aulas y lo que logramos producir en los estudiantes. Porque entre las cosas emocionantes para un niño y un joven, está el ver a un maestro apasionado por lo que hace, por lo que comparte, transformando su pedagogía en arte. (E-2).

Es papel del docente de Lenguaje conducir esa necesidad hacia un amor por el español, por su gramática y su ortografía y, mucho más importante, por la lectura. Cuando en el aula hay docentes con un acendrado amor por el acto de leer es fácil lograr transmitírselo a sus jóvenes estudiantes; esa será la mejor semilla que se podrá plantarles $y$, a veces, la más útil.

Lastimosamente, considero que la universidad y más la carrera que elegí no nos preparó realmente bien para este apostolado comunicativo. (E-17).

En el caso específico de la educación lingüística, los docentes tienden a traducir la conducción de las emociones, que sería la enseñanza, hacia la valoración de la lengua como parte de la identidad propia y, sobre todo, de la lectura en el sentido de la emocionalidad estética. En E-17, por ejemplo, la reiteración del amor por el lenguaje y la lectura se presenta como la clave de la relación didáctica. Desde esa perspectiva, la metáfora de la siembra activa la imagen del docente como el sembrador de semillas y el apóstol de la comunicación ${ }^{7}$. En ese mismo relato, que el docente titula como "Resignificando vidas", queda representada una tendencia de las construcciones ethoticas encontradas: la didáctica de la lengua materna debe contribuir a que los estudiantes den significado a sus vidas personales, esto es, debe formar personas para la vida. De ahí que el posicionamiento del docente frente a sus estudiantes suela estar atravesado por sentimientos de profunda empatía:

La mayor enseñanza se basa en comprender que, si para un adulto que ya sabe responder frente a la burla de sus compañeros con altura, es difícil el ridículo en el aula, hay que ponerse en el lugar de un niño que tiene miedo, además de las burlas de sus compañeros [...] también del castigo físico de los padres; o de las críticas de las personas cercanas al hogar por la mala nota; y el temor a recriminaciones verbales. Esa situación, seguramente, no le permite aprender estrategias para captar los conocimientos; el bloqueo mental impide su aprendizaje. (E-12).

La inscripción de las emociones o del pathos construido se ve imbricada en la construcción del ethos del formador. Los docentes se muestran como sujetos emotivos y empáticos que tratan de ponerse en el lugar de sus alumnos para comprender sus procesos y dificultades de aprendizaje. En esta pretensión, la enseñanza desborda lo disciplinar y arriba a la necesidad de conmoverse con el otro y de exponerse directamente como sujetos afectados. El relato de E-2 es especialmente representativo de esa articulación entre ethos y pathos dichos:

Cuando iba para el salón del grado 10-02 aquel miércoles en la mañana sentí miedo, sentí emoción. Iba a la clase de unos jóvenes con edades contemporáneas a la mía, ¿qué pensarán de la nueva maestra? ¿Serán todos rebeldes? o ¿será que me rechazarán? [...] Resúmenes, evaluaciones y textos escritos por los estudiantes, dan cuenta de

7 La influencia del interdiscurso religioso y pastoral en el imaginario de la profesión docente en Latinoamérica tiene aún plena vigencia y suele quedar involucrado tanto en los relatos docentes como en la interpretación de esas escrituras en torno a la identidad profesional, como lo evidencia el trabajo reciente de Cuenca (2015). 
todo lo que se puede ver en un periodo escolar pero ¿qué pasa con la huella que una obra literaria debe dejar en un estudiante? Y cuando hablo de una huella me refiero a eso que él pueda identificar, nombrar y enriquecer la palabra a través de su experiencia como lector, pero sobre todo como ser humano. (E-2).

El relato reconstruye la experiencia de la primera clase dictada y marca la emocionalidad en torno a las inseguridades naturales del docente novel con respecto a la mirada de sus estudiantes. Esta inscripción pathémica sirve de marco para un relato que se resuelve, más adelante, en una visión de la didáctica de la lengua como acto de dejar huella y de formar seres humanos. En ese proceso de "humanización", el aprendizaje suele ser presentado como un camino de doble vía, desde el aprender juntos:

Por cuatro años trabajé en un colegio de la ciudad de Cali ubicado en la zona oriente, lugar con alta población afrodescendiente, originarios de Buenaventura, Chocó, pero también desplazados del Cauca, Caquetá, Putumayo entre otros [...]. La idea al educar no es imponer mi visión de vida ni de mi conocimiento y uso de la lengua, hasta el punto de inmovilizar sus formas comunicativas. El reconocer esto me dio la oportunidad de conocer sus idiosincrasias y sus modos de pensar; así, aprendieron ellos y también yo. Les hablé de la necesidad de verse involucrados en procesos sociales más allá de las calles y casas. (E-8).

En los relatos que refieren trabajos con comunidades vulnerables, los docentes enfatizan en esa idea de la apertura a las diferencias idiosincráticas que les exige reflexionar sobre la tensión entre academia y realidad, así como entre visiones de mundo no compartidas. Cuando se abordan estas problemáticas, los relatos docentes se inclinan hacia la valoración del uso de la lengua para trascender realidades sociales inmediatas, bien sea desde el punto de vista estético de la significación, o bien desde una mirada más ética de la comunicación:

Mostréquela forma más adecuada de comunicación es la de carácter conciliatorio, utilizando las palabras adecuadas para no herir a la otra persona; los demás niños del curso observaron y valoraron esa forma de uso de la lengua. Los estudiantes se deben formar para ser seres íntegros, por ello y pensando en su futuro es fundamental que ellos lleguen a la universidad siendo partícipes del respeto hacia los demás, y así crear un ambiente más ameno en la sociedad. (E-4).

Nuestro papel de docentes tiene un gran compromiso social además del académico: seguir invitando y demostrando que a través de las letras y las artes se establece y fortalece ese vínculo social que, por naturaleza, no podemos evitar. (E-2).

La enseñanza de la lengua deviene, entonces, en enseñanza de valores para la interacción social en contextos donde la intersubjetividad deriva en violencia física o verbal. El sentido de la integralidad en la formación se desliza, en estos casos, hacia la integridad en su sentido ético, y el docente se presenta a sí mismo como un sujeto comprometido con la formación de los valores que garantizarían esa ética comunicativa para que los vínculos sociales no se rompan. El discurso de la acción-comunicación como interacción racional y resolución razonada de las diferencias intersubjetivas subyace a la construcción del ethos formador, especialmente - pero no únicamente- cuando el docente habla desde su inserción en contextos de sociabilidad frágil. En tales casos, se tiene certeza de que los saberes lingüísticos deben ser, ante todo, saberes para la vida en contexto:

Me he dado a la tarea de enseñarles a comprender, interpretar y analizar textos a través del contexto. Esto se elabora para que los estudiantes, sin importar su grado o su edad, tengan la habilidad y la destreza de argumentar según la situación que se genere en su cotidianidad. (E-6).

Desde esta perspectiva, el ethos del formador para la vida especifica que su tarea autoimpuesta se refiere a la vida en concreto, en su cotidianidad, como lo deja claro E-6. No se trata, pues, de la visión abstracta de las competencias generales para comprender y producir textos, sino de la vinculación de las didácticas de la lectura y la escritura con el mundo de la vida de los estudiantes. En los relatos de los profesores, ellos se declaran intencionalmente 
orientados hacia esa tarea y, con ello, esperan impactar socialmente en las comunidades donde desarrollan su quehacer.

\section{A modo de conclusión}

Las imágenes que los profesores construyen de sí mismos a través de la escritura de sus experiencias están en gran medida vinculadas con el problema de la identidad profesional docente, como se viene estudiando desde ámbitos sociológicos y pedagógicos. El uso del ethos, como categoría analítica para abordar el discurso profesoral, abona a la comprensión de las relaciones que tejen los docentes entre las representaciones sociales (modelos, esquemas, tradiciones, percepciones y estereotipos) externas e internas sobre la profesión que desempeñan. Hay consenso en que uno de los factores que forma parte de la construcción de la identidad profesional docente está asociado con el ámbito de sus autopercepciones conectadas con su entorno profesional y personal. El ethos (dicho y mostrado) permite ver cómo se traducen discursivamente esas autopercepciones y cómo se ponen en escena, a través de qué resaltes y de qué mitigaciones, en el decir de los profesores.

En la exploración realizada, hemos mostrado que el ethos del docente se compone de un conjunto de roles sociales que los profesores apropian como parte de su quehacer y de su posicionamiento en la dinámica educativa, en general, y en los procesos didácticos de enseñanza y aprendizaje de la lengua materna, en particular. Las escrituras de los docentes imbrican ese conjunto de roles en los órdenes del contar y del comentar sus experiencias vitales, al presentarse a sí mismos como profesionales críticos, intelectuales innovadores y formadores para la vida.

Pensamos esas diversas formas del ethos del docente como la apropiación de roles sociales que, desde sus voces propias, los profesores se atribuyen - a veces como compromisos programáticos y a veces como prácticas instaladas en su quehacertras las líneas de sus relatos. El profesional crítico destaca la importancia de posicionar su desacuerdo frente a algunas dinámicas educativas; el intelectual innovador convierte esos diagnósticos negativos en bases sobre las cuales se proponen iniciativas transformadoras en las aulas; el formador para la vida busca que los ejercicios didácticos trasciendan la enseñanza y aprendizaje de la lengua hacia la tarea misional de humanización, en cada contexto problemático. Estos roles sociales se presentan enlazados entre sí y como subsidiarios de la experiencia docente, es decir que aparecen como aspectos del sujeto que es profesional en tanto que ha vivenciado la enseñanza en situaciones reales. En este sentido, la valoración positiva de la experiencia determina la lógica en la construcción del ethos del docente y difumina las fronteras entre el sujeto experimentado y el sujeto experto.

En la bibliografía pedagógica, en gran medida, se considera que la profesión docente involucra un tipo de conocimiento fundamentado en las prácticas. De igual forma, existen líneas de trabajo alrededor de lo que se ha denominado "conocimiento práctico" en la profesión docente que aborda problemáticas epistemológicas en términos de la necesidad de una "teoría de la experiencia", como ya lo apuntaba Dewey desde 1938. La influencia de los saberes previos, las estructuras conceptuales y las teorías implícitas del docente, que le dan sentido a sus experiencias didácticas y, por tanto, al conocimiento que construye a partir de ellas (Eisner, 1988; Gimeno Sacristán, 1997). La reflexividad como la clave de la formación de docentes que sean capaces de aprender en y a través de las prácticas (Schön, 1987; Perrenoud, 2007). La escuela y los lugares de iniciación profesional docente como espacios de aprendizaje continuo (Davini, 2002). El problema del reconocimiento y de la legitimación del saber didáctico como saber autorizado (Terigi, 2012), entre otras cuestiones.

En este artículo, sumamos un aspecto por explorar en esa línea de trabajo, desde una visión interdisciplinar entre el análisis del discurso y la didáctica: la construcción que el docente hace de sí mismo como un sujeto de la experiencia, esto es, un ethos docente cuya dominancia estriba en hacer de las prácticas reales en las aulas la fuente de su profesionalización: la convicción, puesta en el ethos, de que la experiencia hace al maestro. 
En una parte del proyecto de investigación que enmarca este artículo nos interesó escuchar las voces de los docentes en ejercicio, después de haber pasado por cinco o más años de preparación universitaria para la enseñanza de la lengua materna. Un aspecto que emerge de ese interés es el análisis de sus construcciones retóricas a través de las cuales relacionan ethos y pathos particulares al hablar de sí mismos como profesionales, y de la didáctica de la lengua materna que van construyendo como saberes de la experiencia.

Estamos de acuerdo con Hargreaves (1996) en que no se trata de posicionar esos testimonios y las citas que los ejemplifican como "la voz" monocorde del docente, por el contrario, reconocemos una diversidad de acentos en la construcción de la imagen que ellos presentan de sí mismos; este artículo no pretende ni describirlos exhaustivamente ni agotarlos, sino hacer una exploración inicial en esas voces. Del mismo modo, no nos interesó asumir una postura evaluativa al respecto de sus palabras o sus modos de decir y construir su imagen, sino aproximarnos a ellas desde una perspectiva interpretativa y comprensiva. Esperamos que esta mirada, en ciernes, contribuya y motive a pensar desde el cruce interdisciplinar el problema de la identidad docente, para seguir leyendo y escuchando lo que ellos tienen para decir, que no es poco.

\section{Referencias}

Alliaud, A. (1998). El maestro que aprende. Ensayos y experiencias. Buenos Aires: Novedades Educativas.

Amossy, R. (2010). La présentation de soi. Ethos et identité verbale. París: PUF.

Aristóteles (2010). El arte de la retórica. Buenos Aires: Eudeba.

Arostegui, J. (2004). La historia vivida. Sobre la historia del presente. Madrid: Alianza.

Bolívar, A. (2014). Las historias de vida del profesorado: Voces y contextos. Revista Mexicana de Investigación Educativa, 19(62), 711-734.

Bolívar, A. y Domingo, J. (2006). La investigación biográfica y narrativa en Iberoamérica: Campos de desarrollo y estado actual. Forum: Qualitative Social Research, 7(4), 1-43.
Castelló, M. (coord.) (2007). Escribir y comunicarse en contextos científicos y académicos: Conocimientos y estrategias. Barcelona: Graó.

Chevallard, Y. (1991). La transposición didáctica. Del saber sabio al saber a enseñar. Buenos Aires: Aiqué.

Cisneros-Estupiñán, M., Rojas-García, I. y Olave-Arias, G. (2016a). Didáctica de la lengua materna en Colombia. Currículos y visiones docentes. Pereira: Universidad Tecnológica de Pereira.

Cisneros-Estupiñán, M., Rojas-García, I. y Olave-Arias, G. (2016b). Hacia la desfragmentación de la didáctica de la lengua materna. Pereira: Universidad Tecnológica de Pereira.

Clementino de Souza, E., Serrano, J. A. y Ramos, J. M. (comp.) (2014). Monográfico sobre autobiografía y educación. Revista Mexicana de Investigación Educativa (RMIE), 19(62), 683-883.

Cuenca, R. (2015). La misión sagrada. Un estudio sobre la identidad profesional de los docentes (tesis inédita de doctorado). Universidad Autónoma de Madrid, Madrid, España.

Davini, M. (coord.) (2002). De aprendices a maestros. Enseñar y aprender a enseñar. Buenos Aires: Papers editores.

Dewey, J. (1938). Experience \& education. Illinois: Kappa Delta Pi.

Eisner, E. (1988). El ojo ilustrado. Barcelona: Paidós.

Esteve, J. (1987). El malestar docente. Barcelona: Laia.

Gimeno Sacristán, J. (1997). Docencia y cultura escolar. Reformas y modelo educativo. Buenos Aires: Ideas.

Goodson, I. (2003). Hacia un desarrollo de las historias personales y profesionales de los docentes. Revista Mexicana de Investigación Educativa, 8(19), 733-758.

Goodson, I. (2012). Developing narrative theory: Life history and personal representation. Londres y Nueva York: Routledge.

Hargreaves, H. (1996). Revisiting voice. Educational Researcher January, 25, 12-19.

Jackson, P. (1996). La vida en las aulas. Madrid: Morata.

McEwan, H. y Egan, K. (comp.) (1998). La narrativa en la enseñanza, el aprendizaje y la investigación. Buenos Aires: Amorrortu editores.

Maingueneau, D. (2009). El enunciador encarnado. La problemática del ethos. Versión, UAM-X, 24, 203-225.

Maingueneau, D. (2014). Discours et analyse du discours. Introduction. París: Armand Colin. 
Montemayor-Borsinger, A. (2004). Tema. Una perspectiva funcional de la organización del discurso. Buenos Aires: Eudeba.

Montero, A. S. (2012). Los usos del ethos. Abordajes discursivos, sociológicos y políticos. Rhétor, 2(2), 223-242.

Perrenoud, P. (2007). Desarrollar la práctica reflexiva en el oficio de enseñar Profesionalización y razón pedagógica. Barcelona: Graó.

Rivas, J., Sepúlveda, M. y Rodrigo, P. (2005). La cultura profesional de los docentes en enseñanza secundaria: un estudio biográfico. Archivos Analíticos de Políticas Educativas, 13(49), 1-29.

Schön, D. (1987). La formación de profesionales reflexivos. Hacia un nuevo diseño de la enseñanza y el aprendizaje en las profesiones. Barcelona: Paidós.

Strauss, A. y Corbin, J. (2002). Bases de la investigación cualitativa: técnicas y procedimientos para desarrollar la teoría fundamentada. Medellín: Editorial Universidad de Antioquia.
Tedesco, J. y Tenti, E. (2006). Nuevos tiempos y nuevos docentes. En Sindicato Nacional de Trabajadores de la Educación (comp.), IV Congreso Nacional de Educación. Documentos de discusión, Tomo II (pp. 57-82). México: Ciudad de México.

Terigi, F. (2012). Los saberes docentes. Formación, elaboración en la experiencia e investigación. Buenos Aires: Santillana.

Tezanos, A. (2012). ¿Identidad y/o tradición docente? Apuntes para una discusión. Revista Perspectiva Educacional, 51(1), 1-28.

Vaillant, D. (2007). La identidad docente. La importancia del profesorado. I Congreso Internacional Nuevas Tendencias en la Formación Permanente del Profesorado, 5-7 de septiembre, Barcelona, España.

Para citar este artículo

Cisneros, M., Olave, G., y Rojas, L. (2017). Exploración del ethos del docente de español en Colombia.

Folios, (46), 129-143. 